\title{
Comparison of models for predicting nitrification, denitrification and nitrous oxide emissions in pastoral systems
}

\author{
Iris Vogeler ${ }^{a}$, Donna Giltrap ${ }^{\mathrm{b}}$, Frank Li ${ }^{\mathrm{a}}$, and Val Snow \\ ${ }^{a}$ AgResearch, Grasslands Research Centre, Palmerston North, New Zealand \\ ${ }^{b}$ Landcare Research, Palmerston North, New Zealand \\ ${ }^{c}$ AgResearch, Lincoln Research Centre, Lincoln, Lincoln, New Zealand \\ Email: iris.vogeler@agresearch.co.nz
}

\begin{abstract}
Intensification of agricultural systems has resulted in remarkable increases in productivity. However in grazed systems only about $10-20 \%$ of the $\mathrm{N}$ ingested by grazing animals is retained in animal products. The reminder is returned in excreta to the paddock in a spatially non-uniform fashion as dung and urine and then either accumulates in the soil or is lost via leaching or gaseous emissions. The amount of $\mathrm{N}$ lost from these patches via leaching and gaseous emissions is highly dependent on site-specific factors. Routine direct measurements are impractical given the scale and variability so simulation models are an essential alternative to estimate likely $\mathrm{N}$ losses. Various simulation approaches are in use or are being developed to predict $\mathrm{N}$ leaching and $\mathrm{N}_{2} \mathrm{O}$ emissions. The models vary in the level of detail or number of nitrogen pools and transformation processes considered, as well as on how the processes are described. Other processes within the models, such as water and heat transport within the soil also affect the modelled N transformations and losses. While most models have been tested and validated for some processes or outputs in a particular range of systems, soils and climates, there is a lack of information on how models compare in other aspects. We discuss key differences and similarities between the $\mathrm{N}$ transformation components of the APSIM and DNDC models with respect to their simulation of nitrification, denitrification and $\mathrm{N}_{2} \mathrm{O}$ emissions under pastoral systems.
\end{abstract}

Agreement between daily $\mathrm{N}_{2} \mathrm{O}$ emissions from urine patches simulated by APSIM and DNDC was variable, Figure 1. For the Horotiu soil the index of agreement (IA) between measurements and APSIM or DNDC were 0.4 and 0.13 , and for the Templeton soil 0.77 and 0.47 . Agreement between total emissions over the experimental period was better for the APSIM model than the DNDC, based on default model parameters. For the Horotiu soil, $\mathrm{N}_{2} \mathrm{O}$ emissions over 3 months were $4.9 \mathrm{~kg} / \mathrm{ha}$, and simulations with APSIM and DNDC gave values of 7.4 and $13.7 \mathrm{~kg} / \mathrm{ha}$. For the Templeton soil over 1 year measurements were $2.8 \mathrm{~kg} / \mathrm{ha}$ and simulations with APSIM $1.9 \mathrm{~kg} / \mathrm{ha}$ and with DNDC $16.3 \mathrm{~kg} / \mathrm{ha}$. Adjusting default values to NZ conditions can, however, improve the prediction capacities of the models.

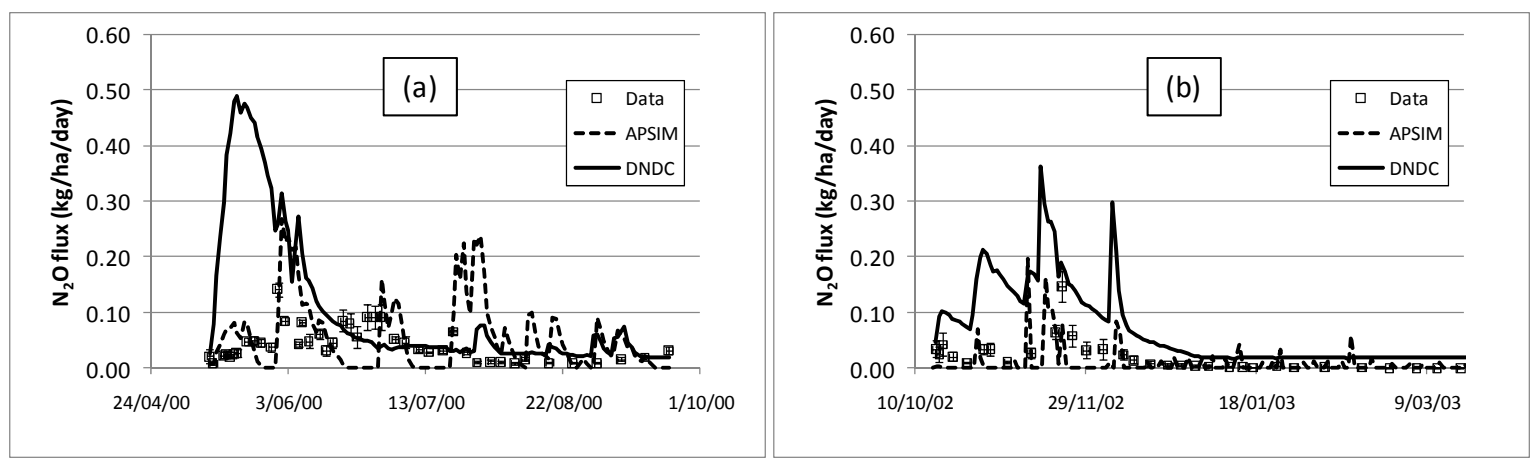

Figure 1. Measured and simulated $\mathrm{N}_{2} \mathrm{O}$ emission from a urine patch by APSIM and DNDC a) Horotiu silt loam over 4 months and b) Templeton silt loam over 1 year from New Zealand (data taken from de Klein et al., 2003)

Keywords: APSIM, DNDC, nitrous oxide, nitrification, denitrification 


\section{INTRODUCTION}

Nitrogen cycling in terrestrial ecosystems is complex and includes microbial processes such as mineralisation, nitrification and denitrification, plant physiological processes (nitrogen uptake and assimilation) and physicochemical processes (leaching, volatilisation). These various processes are affected by environmental conditions such as soil oxygen and moisture contents, temperature, mineral $\mathrm{N}$ content, available carbon and $\mathrm{pH}$. The complexity of these various interconnected processes combined with a large spatial and temporal variation in transformation rates involved in nitrogen cycling processes bedevils quantification of $\mathrm{N}$ losses via leaching, volatilisation and nitrous oxide $\left(\mathrm{N}_{2} \mathrm{O}\right)$ emissions from all agricultural systems but is particularly challenging in pastoral systems because the grazing ruminants effectively redistribute the nitrogen from the plants into high-concentration excreta patches. The resulting heterogeneity in the soil-plant system means that whole paddocks cannot appropriately be modelled at a process level using paddock averages.

Various models have been developed that integrate process-based knowledge of nitrogen and carbon cycling in the soil-plant atmosphere continuum. Such models offer the potential to decipher the contribution of individual components to the total system and can help to better understand how environmental conditions combined with management strategies interact to control nitrogen cycling and $\mathrm{N}$ losses. Inter-model comparison offers another possibility for better understanding the complex and interacting processes.

The Agricultural Production Systems Simulator, (APSIM; Keating et al., 2003), and DeNitrification DeComposition, (DNDC; Li et al., 1992) are models that provide process-level descriptions of nitrogen cycling and provide, besides many other outputs, daily values for $\mathrm{N}$ transformation rates and losses. These two models have different strengths in scale and loss pathways. APSIM has been developed to simulate the biological and physical processes in farming systems, initially with an emphasis on cropping systems, but lately also for pasture systems with the possibility of simulating at the urine patch as well as multi-paddock scale (Li et al., 2010; Vogeler et al., 2010). DNDC model has been initially developed for simulating $\mathrm{N}_{2} \mathrm{O}$, $\mathrm{CO}_{2}$ and $\mathrm{N}_{2}$ emissions and denitrification from cultivated and grassland sites, but later improved for simulation water flow and nitrate leaching (Li et al., 2006) and other systems such as perennial pastures and $\mathrm{N}_{2} \mathrm{O}$ emissions from dairy-grazed pasture in New Zealand (Saggar et al., 2004). In both models, processes such as nitrification and denitrification are represented as functions of nitrogen and available carbon, and modified by dimensionless factors for soil water content and temperature. The description of $\mathrm{N}$ transformations in these two models is, however, conceptually different. While in APSIM the processes of nitrification and denitrification are described via empirical reaction equations, expressed via a MichaelisMenten type equation, DNDC is a microbial growth model.

The objective of this model comparison is to identify primary differences in simulated nitrogen transformation rates in soils under varying environmental conditions including temperature, soil water content, soil organic carbon, $\mathrm{pH}$, and initial $\mathrm{NH}_{4}$ and $\mathrm{NO}_{3}$ concentration. To begin, a short description of the two models is given. To eliminate the effect of water flow on these transformation processes simulations were first done under static conditions. In the second comparison rainfall and drainage were included. Finally model predictions were compared to published laboratory and field measurements.

\section{MODEL DESCRIPTION AND SIMULATION SETUP}

\subsection{APSIM}

APSIM is a framework of biophysical modules that simulate biological and physical processes in farming systems (Keating et al., 2003). The SoilN module simulates the dynamics of $\mathrm{N}$ and $\mathrm{C}$ on a daily time-step in soil layers, with $\mathrm{C}$ and $\mathrm{N}$ mineralisation, $\mathrm{C}$ and $\mathrm{N}$ immobilisation, $\mathrm{N}$ nitrification, $\mathrm{N}$ denitrification and nitrate and ammonium adsorption and movement explicitly described in each layer. These $\mathrm{N}$ processes are controlled by soil water content, temperature and $\mathrm{pH}$ and water flow which are simulated within either the SoilWat (Probert et al., 1998) or SWIM (Verburg et al., 1996) modules. For all simulations APSIM Version 7.4 was used.

\subsection{DNDC}

DNDC consists of several sub-models for simulating thermal-hydraulic flows, plant growth, aerobic decomposition, fermentation and denitrification. The model usually operates on a daily time-step, except following a rainfall event where denitrification is calculated on an hourly time-step. To allow nitrification and denitrification to occur simultaneously in aerobic or anaerobic microsites, a dynamic 'anaerobic balloon' balloon' is used ( $\mathrm{Li}$ et al., 2000). Substrates such as carbon, $\mathrm{NH}_{4}$ and $\mathrm{NO}_{3}$ are split into aerobic and 
anaerobic soil micro-sites. The NZ-DNDC (Saggar et al., 2007), a modification of DNDC (Version 8.6K) was used within this model comparison.

\section{3. $\quad \mathrm{N}$ transformations simulations in uniform soil}

To compare $\mathrm{N}$ transformations from the two different simulation approaches, APSIM and DNDC, simulations were set up with uniform soil under a range of static environmental conditions. The soil was a bare sandy loam with a depth of $200 \mathrm{~mm}$. The bulk density of the soil was $1 \mathrm{Mg} \mathrm{m}^{-3}$, total porosity was $59 \%$, $\theta$ at field capacity and permanent wilting point was 0.43 and $0.23 \mathrm{~m}^{3} \mathrm{~m}^{-3}$ and the $\mathrm{C}: \mathrm{N}$ ratio of the humus fraction was 12. Factors that were changed included water flow regime (either static or dynamic), the initial concentration of $\mathrm{NH}_{4}\left(100\right.$ or $500 \mathrm{~kg} / \mathrm{ha}$ ) with $10 \mathrm{~kg} \mathrm{NO}_{3} / \mathrm{ha}$, or $1 \mathrm{~kg} \mathrm{NH}_{4} / \mathrm{ha}$ with $100 \mathrm{~kg} \mathrm{NO}$ (uniform within the soil), $\theta$ of $0.3,0.45$, and $0.55 \mathrm{~m}^{3} \mathrm{~m}^{-3}$, soil temperature of 10,15 and $30^{\circ} \mathrm{C}$, soil organic carbon content of 3 and $6 \%$, pH of 6 and 8 , with or without rainfall of either $20 \mathrm{~mm}$ on day 1 , or at $5 \mathrm{~mm} /$ day. The simulations were run for 10 days and simulation output included cumulative and daily values of nitrification, denitrification, and $\mathrm{N}_{2} \mathrm{O}$ and $\mathrm{N}_{2}$ emissions.

\subsection{Nitrification simulation - comparison against measurements}

Nitrification simulated with APSIM and DNDC were compared to two incubation studies done under controlled conditions in a silt loam (Di and Cameron, 2004) and a loam and clay loam (Rovita and Killorn, 2007). The nitrification was inferred from the temporal decrease of $\mathrm{NH}_{4}$ in the soil.

\subsection{Simulation of $\mathrm{N}_{2} \mathrm{O}$ emissions from urine patches-comparison with measured $\mathrm{N}_{2} \mathrm{O}$ data}

APSIM and DNDC were used to simulate $\mathrm{N}_{2} \mathrm{O}$ emissions following urine application to two different soil types in two different seasons. The simulations were compared to selected experimental results, described in detail by de Klein et al. (2003). In short, the selected experiments were done in the Waikato region of New Zealand on a free draining Horotiu silt loam and in the Canterbury region on a moderately drained Templeton silt loam. Urine, at a concentration of about $600 \mathrm{~kg} / \mathrm{ha}$, was applied in autumn 2000 to the Horotiu soil and in spring 2002 to the Templeton soil.

\subsection{Statistical analysis}

To evaluate the agreement between simulation results of APSIM and DNDC, as well as between the models and measurements the correlation coefficient and the Index of Agreement (IA) proposed by (Willmott et al., 1985) as an alternative to correlation coefficients. IA is a relative and varies between 0 for no agreement at all and 1 for a perfect match.

\section{RESULTS}

\section{1. $\quad \mathbf{N}$ transformations simulations in uniform soil}

\section{Nitrification}

Nitrification of the initial $\mathrm{NH}_{4}\left(\mathrm{NH}_{4}\right.$ ini) in the soil as simulated by APSIM and DNDC were quite different with a high initial nitrification rate and a steep decline in $\mathrm{NH}_{4}$ simulated by DNDC and a relatively constant nitrification rate over the 10 day simulation run for APSIM. This is shown in Figure 2a for a simulation run under static conditions, a temperature of $10^{\circ} \mathrm{C}$ and $\mathrm{NH}_{4}$ ini of $500 \mathrm{~kg} / \mathrm{ha}$. In general, the agreement improved with decreasing $\mathrm{NH}_{4}$ ini and increasing temperature (Figure $2 \mathrm{~b}$ ). This is mainly due to a much greater response of APSIM to temperature, as can be seen from the simulated nitrification of $\mathrm{NH}_{4}$ of $30 \mathrm{~kg} / \mathrm{ha}$ over a period of 10 days (Figure 3a) with the 12 combinations of factors $(\mathrm{pH}, \mathrm{OC}, \theta)$. In contrast DNDC reacted more strongly to $\theta$, showing decreasing nitrification with increasing $\theta$ over the range of water contents studied (Figure 3b). DNDC also showed a reduction in nitrification rate as $\mathrm{pH}$ increased from 6 to 8 (data not shown), whereas that $\mathrm{pH}$ range is considered to be uniformly optimal with APSIM's default settings.

\section{Denitrification}

Denitrification from the simulations done under dynamic conditions and with an initial $\mathrm{NO}_{3}$ concentration of $100 \mathrm{~kg} / \mathrm{ha}$ shows increasing rates with time for DNDC, while decreasing rates for APSIM (Figure 4). For denitrification DNDC shows a stronger influence of temperature and organic carbon than does APSIM (Figure 5). While in APSIM denitrification only occurs at $\theta \geq$ field capacity, and thus equals zero in the simulations done at $\theta$ of 0.3 , in DNDC denitrification is triggered by rainfall $\geq 5 \mathrm{~mm}$. 


\section{$\mathrm{N}_{2} \mathrm{O}$ emissions}

Simulated $\mathrm{N}_{2} \mathrm{O}$ emissions from DNDC and APSIM show a similar trend as did denitrification, with an increasing rate for DNDC and a slightly decreasing rate for APSIM over the 10 days (Figure 4b). Similar to denitrification DNDC shows a larger response to temperature and organic carbon content (data not shown).

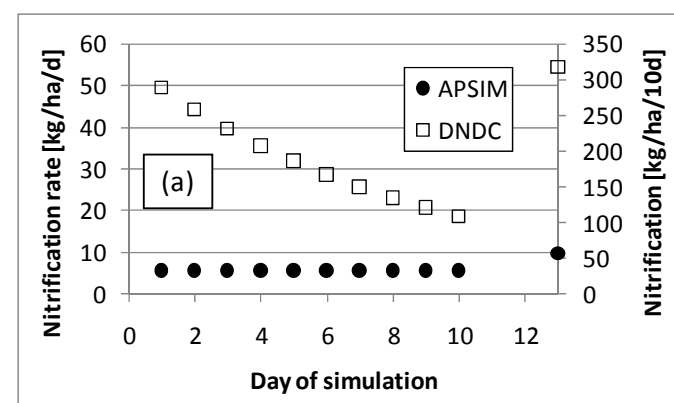

$\mathrm{T}=10^{\circ} \mathrm{C} \theta=0.45 \mathrm{~m}^{3} \mathrm{~m}^{-3} \mathrm{SOC}=6 \% \mathrm{pH}=6$ $\mathrm{NH}_{4}$ ini $=500 \mathrm{~kg}$ ha $\quad \mathrm{IA}=0.36$

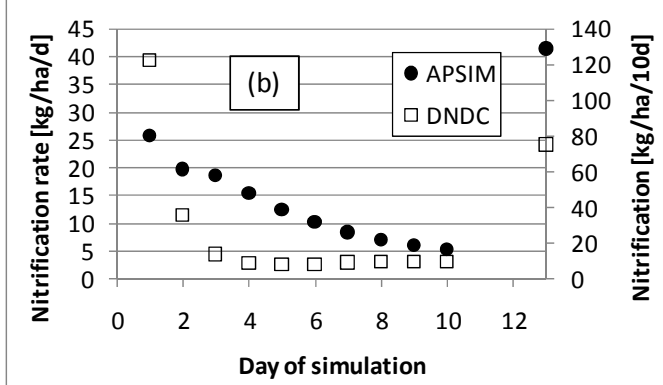

$\mathrm{T}=30^{\circ} \mathrm{C} \theta=0.45 \mathrm{~m}^{3} \mathrm{~m}^{-3} \mathrm{SOC}=6 \% \mathrm{pH}=6$ $\mathrm{NH}_{4}$ ini $=100 \mathrm{~kg} \mathrm{ha}^{-1} \mathrm{RF}=20 \mathrm{~mm} @ \mathrm{D} 1 \mathrm{IA}=0.75$

Figure 2. Nitrification rate simulated by APSIM and DNDC over 10 days in a silt loam under a) static conditions and b) a rainfall event of $20 \mathrm{~mm}$ on day 1. Also shown, on the right axis, is the total nitrification over 10 days.
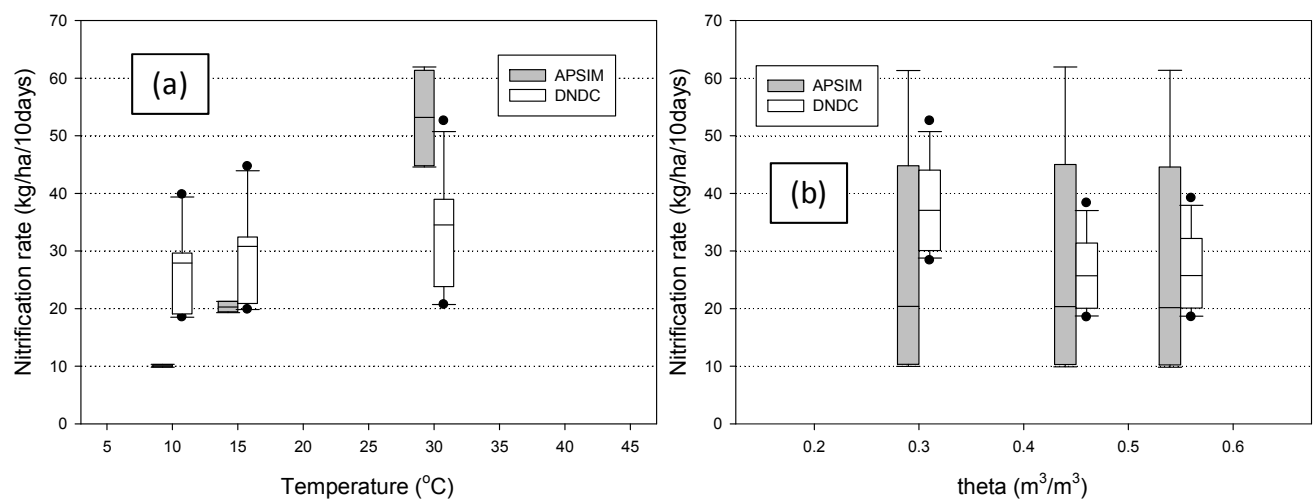

Figure 3. Nitrification over 10 days as simulated by APSIM and DNDC for a sandy loam with an initial $\mathrm{NH}_{4}$ of $30 \mathrm{~kg} / \mathrm{ha}$ under dynamic conditions as influenced by a) temperature and b) soil water content. The boxes show the 25th, 50th, and 75th percentiles, and the whiskers the 5th and 95th percentiles model outputs from 12 different combinations of a) $\mathrm{pH}, \mathrm{OC}$ and $\theta$ and b) $\mathrm{pH}, \mathrm{OC}$, and $\mathrm{T}$.
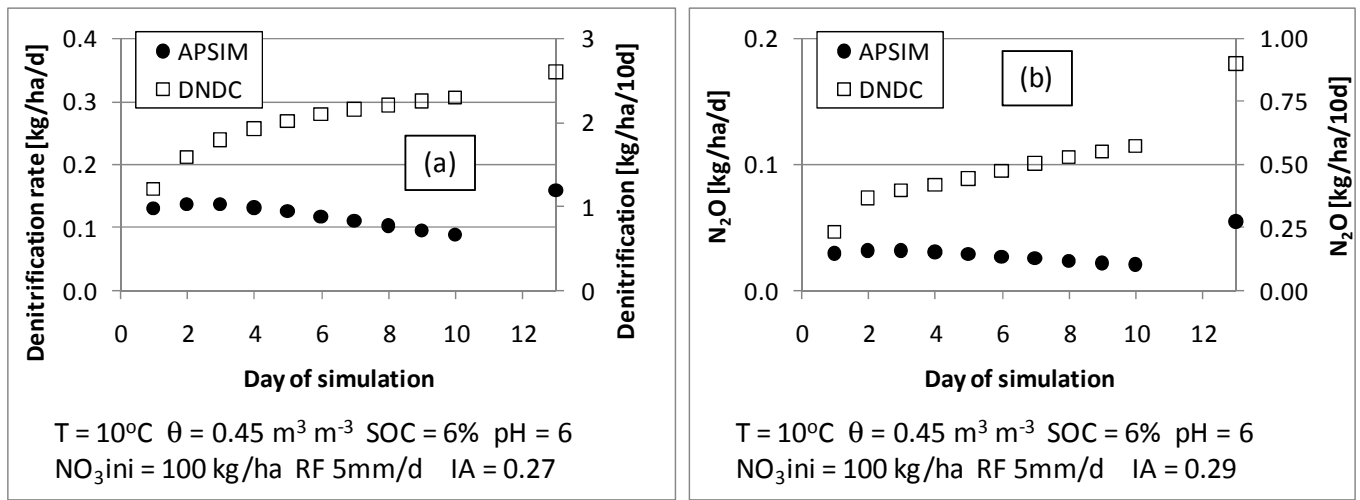

Figure 4. a) Denitrification rate and b) $\mathrm{N}_{2} \mathrm{O}$ emission simulated by APSIM and DNDC over 10 days in a silt loam with a rainfall of $5 \mathrm{~mm} /$ day. 

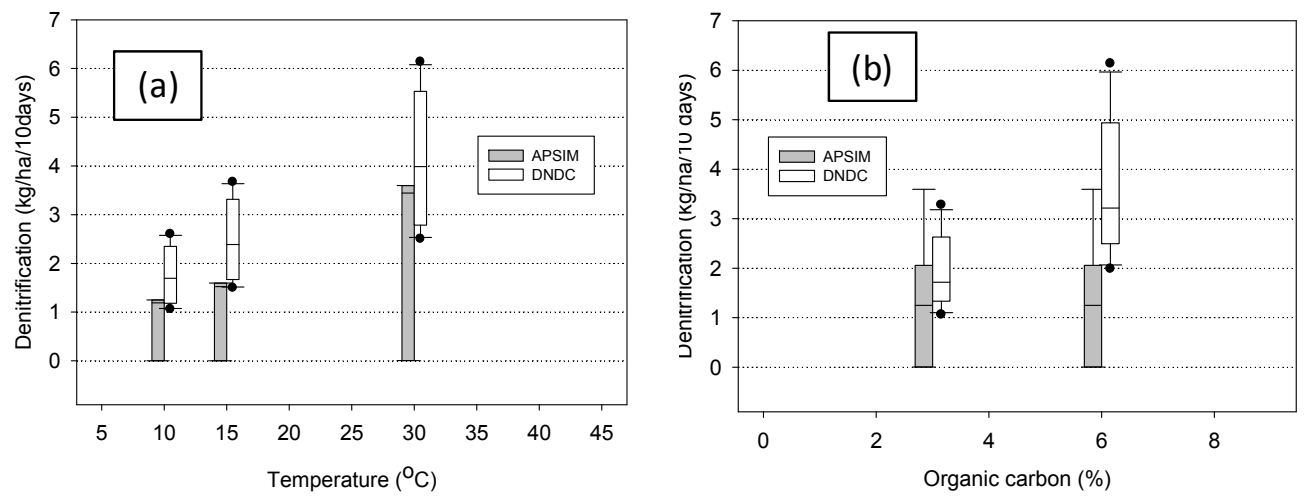

Figure 5. Denitrification over 10 days as simulated by APSIM and DNDC for a sandy loam under dynamic conditions as influenced by a) temperature and b) soil organic carbon content as influenced by a) temperature and b) soil organic carbon content (SOC). Each temperature and organic carbon content comprises model outputs from 12 different combinations of a) $\mathrm{pH}, \mathrm{OC}$ and $\theta$ and b) $\mathrm{pH}, \theta$, and $\mathrm{T}$.

\subsection{Nitrification simulation - comparison with measured data}

Neither of the models showed a close agreement with the nitrification data. The closest agreement between models and data was for APSIM compared to the Di and Cameron (2004) data at $20^{\circ} \mathrm{C}$ and the Rovita and Killorn (2007) loam data (Figure 6). APSIM badly under predicted nitrification at 8 C (Figure 6a) and had the wrong direction of response to the clay compared to the loam soil (Figure 6b). DNDC consistently overpredicted nitrification rates and showed little effect of $\mathrm{NH}_{4}$ concentration, soil or temperature on the nitrification rate. (Figure 6).

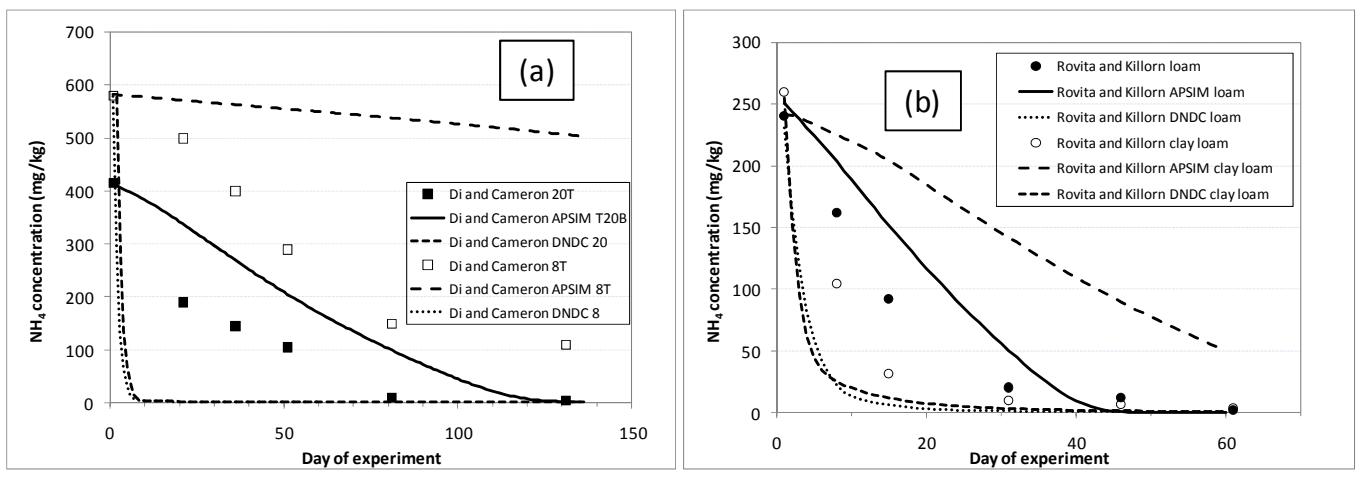

Figure 6. Comparison of measured and simulated nitrification by APSIM and DNDC for a) a silt loam from New Zealand (Di and Cameron, 2004) and b) a loam and clay loam from Iowa, USA (Rovita and Killorn, 2007).

\subsection{Simulation of $\mathrm{N}_{2} \mathrm{O}$ emissions from urine patches - comparison with measured $\mathrm{N}_{2} \mathrm{O}$ data}

Agreement between $\mathrm{N}_{2} \mathrm{O}$ emissions simulated by APSIM and measured from urine patches on the Horotiu soil was reasonably good considering the large variability in measured values (Figure 1 and Table 1). While the simulation of the variation in $\mathrm{N}_{2} \mathrm{O}$ emissions with time is not as good, with low IA's (Table 1) the agreement of the total $\mathrm{N}_{2} \mathrm{O}$ emission over the period of about 4 months is reasonably good. Measured emissions ranged from $3.9-6.4 \mathrm{~kg} / \mathrm{ha}$ and were slightly higher at $7.4 \mathrm{~kg} / \mathrm{ha}$ for APSIM. For the simulations it was assumed that the $\mathrm{N}_{2} \mathrm{O}$ produced within the top $200 \mathrm{~mm}$ is released into the atmosphere, as suggested by $\mathrm{Li}$ et al. (2007) for denitrification. The agreement between $\mathrm{N}_{2} \mathrm{O}$ emissions measured and predicted by DNDC is very poor for the Horotiu soil, with total emissions of $13.7 \mathrm{~kg} / \mathrm{ha}$, more than double the measured amount and a large surge shortly after urine application. For the Templeton soil the agreement between APSIM and measurement was better for both the IA and the total $\mathrm{N}_{2} \mathrm{O}$ emission, with measurements ranging from 1.7 to $4.6 \mathrm{~kg} / \mathrm{ha}$ and APSIM simulation of $1.9 \mathrm{~kg} / \mathrm{ha}$. DNDC, using default parameters, again overpredicted emissions, but the daily trend in $\mathrm{N}_{2} \mathrm{O}$ emission was similar to the measured data, indicated by the higher IA for the Templeton soil than the Horotiu soil. 
The question arises why APSIM and DNDC show a similar trend in $\mathrm{N}_{2} \mathrm{O}$ emissions from urine patches for the Templeton soil, but a large initial discrepancy for the Horotiu soil, especially shortly following urine application. Initial nitrification under the urine patches is, as suggested from the results presented above, higher in DNDC than APSIM, due to both the high initial $\mathrm{NH}_{4}$ concentration and the average temperatures of 13 (Horotiu) and $11.8^{\circ} \mathrm{C}$ (Templeton) within the first 14 days. Denitrification is also likely to be higher in DNDC compared with APSIM (Figure 5), but more similar for the Templeton soil with an organic carbon content of $3 \%$, compared with the Horotiu soil with an $\mathrm{OC}$ of $5.8 \%$. However more analysis is required to fully understand the interactions between nitrification and denitrification, and the many other interconnected processes that affect the fate of $\mathrm{N}$ in pastoral systems, including volatilisation, movement of $\mathrm{NO}_{3}$ and $\mathrm{NH}_{4}$ in the soil, and their uptake by plants, as well as the partitioning of the denitrified $\mathrm{N}$ into $\mathrm{N}_{2}$ and $\mathrm{N}_{2} \mathrm{O}$, and how this finally influences $\mathrm{N}_{2} \mathrm{O}$ production and emissions as simulated by APSIM and DNDC.

Table 1. Comparison of measured (average and range), and simulated gaseous $\mathrm{N}$ emissions from a urine patch by APSIM and DNDC for a Horotiu silt loam over 4 months and a Templeton silt loam over 1 year from New Zealand (de Klein et al., 2003) with units of $\mathrm{kg} / \mathrm{ha}$.

\begin{tabular}{|l|l|l|l|l|l|l|l|l|}
\hline & \multicolumn{4}{|c|}{$\mathrm{N}_{2} \mathrm{O}$} & $\mathrm{N}_{2} / \mathrm{N}_{2} \mathrm{O}$ & \multicolumn{2}{c|}{$\mathrm{NH}_{3}$} \\
\hline & measured & $\begin{array}{l}\text { APSIM } \\
(20 \mathrm{~cm})\end{array}$ & $\begin{array}{l}\text { DNDC } \\
(50 \mathrm{~cm})\end{array}$ & IA APSIM & IA DNDC & DNDC & APSIM & DNDC \\
\hline Horotiu & $\begin{array}{l}4.9 \\
(3.9-5.1)\end{array}$ & 7.4 & 13.7 & $\begin{array}{l}0.4 \\
(0.37-0.48)\end{array}$ & $\begin{array}{l}0.13 \\
(0.09-0.19)\end{array}$ & 19.0 & 4.6 & 28.8 \\
\hline Templeton & $\begin{array}{l}2.8 \\
(1.7-4.6)\end{array}$ & 1.9 & 16.3 & $\begin{array}{l}0.77 \\
(0.64-0.83)\end{array}$ & $\begin{array}{l}0.47 \\
(0.31-0.67)\end{array}$ & 20.2 & 7.7 & 18.8 \\
\hline
\end{tabular}

\section{CONCLUSIONS}

This paper presents a comparison of the two different models, APSIM and DNDC to simulate nitrogen transformation rates, including nitrification, denitrification and $\mathrm{N}_{2} \mathrm{O}$ emissions in soils. The comparison included simulation done in uniform soils under static and dynamic conditions, as well as comparison to measured data from published laboratory and field data.

The APSIM- and DNDC-simulated nitrification and denitrification rates over 10 days were quite different. While in APSIM temperature had a larger effect on nitrification, in DNDC the $\mathrm{NH}_{4}$ concentration and the soil water content had more effect. Denitrification DNDC shows a stronger influence of temperature and organic carbon than does APSIM, and in DNDC is triggered by rainfall whereas in APSIM by soil water content. The agreement between simulated nitrification rates and measured data shows variable results. In general DNDC largely over-predicts the measured nitrification rate. APSIM simulations agree under some environmental conditions with measurements but not in others. The comparisons suggest further work is required to better understand the influence of soil organic matter and allophone content on nitrification rates.

Agreements between measured and simulated $\mathrm{N}_{2} \mathrm{O}$ emissions from urine patches were reasonably good, especially considering that the models were run with default parameter values. Agreement between total emissions over the experimental period was better for the APSIM model than the DNDC. For the Horotiu soil, $\mathrm{N}_{2} \mathrm{O}$ emissions over 3 month were $4.9 \mathrm{~kg} / \mathrm{ha}$, and simulations with APSIM and DNDC gave values of 7.4 and $13.7 \mathrm{~kg} / \mathrm{ha}$. For the Templeton soil over 1 year measurements were $2.8 \mathrm{~kg} / \mathrm{ha}$ and simulations with APSIM $1.9 \mathrm{~kg} / \mathrm{ha}$ and with DNDC $16.3 \mathrm{~kg} / \mathrm{ha}$.

In conclusion it should be stressed that for both models only default values for the many model parameters were used. Fine tuning of model parameter values based on measurements and improved understanding is likely to increase the prediction capability of the models, and maybe also the agreement between the two models. For example the model performance could be improved for APSIM by increasing the nitrification rate based on the soil organic carbon content (Snow et al., 2011), and for DNDC by altering the partitioning of the soil organic carbon and increasing the volatilisation rate (Giltrap et al., 2010).

\section{ACKNOWLEDGMENTS}

This project is jointly funded by the New Zealand Agricultural Green House Gas Research Centre (NZAGRC) under "Integrated Systems" and MAF under "Sustainable Land Management Mitigation \& Adaptation to Climate Change". 
Vogeler et al., Comparison of models for predicting nitrification and denitrification in pastoral systems

\section{REFERENCES}

De Klein, C., Barton, L., Sherlock, R.R., Li, Z., and Littlejohn, R.P., 2003, Estimating a nitrous oxide emission factor for animal urine from some New Zealand pastoral soils.: Australian Journal of Soil Research, v. 41, p. 381-399.

Di, H.J., and Cameron, K.C., 2004, Effects of temperature and application rate of a nitrification inhibitor, dicyandiamide (DCD), on nitrification rate and microbial biomass in a grazed pasture soil.: Australian Journal of Soil Research, v. 42, p. 927-932.

Giltrap, D.L., Singh, J., Saggar, S., and Zaman, M., 2010, A preliminary study to model the effects of a nitrification inhibitor on nitrous oxide emissions from urine-amended pasture: Agriculture, Ecosystems and Environment, v. 136, p. 310-317.

Keating, B., Carberry, P., Hammer, G., Probert, M., Robertson, M., Holzworth, D., Huth, N., Hargreaves, J., Meinke, H., Hochman, Z., McLean, G., Verburg, K., Snow, V., Dimes, J., Silburn, M., Wang, E., Brown, S., Bristow, K., Asseng, S., Chapman, S., McCown, R., Freebairn, D., and Smith, C., 2003, An overview of APSIM, a model designed for farming systems simulation: European Journal of Agronomy, v. 18, p. 267-288.

Li, C., Aber, J., Stange, F., Butterbach-Bahl, K., and Papen, H., 2000, A process-oriented model of N2O and NO emissions from forest soils: 1. Model development: Journal of Geophysical Research D: Atmospheres, v. 105, p. 4369-4384.

Li, C., Farahbakhshazad, N., Jaynes, D.B., Dinnes, D.L., Salas, W., and McLaughlin, D., 2006, Modeling nitrate leaching with a biochemical model modified based on observations in a row-crop field in Iowa.: Ecological Modelling, v. 196, p. 116-130.

Li, C., Frolking, S., and Frolking, T.A., 1992, A model of nitrous oxide evolution from soil driven by nitrous oxide evolution from soil driven by rainfall events. Model structure and sensitivity.: Journal of Geophysical Research, v. D9, p. 9776-9799.

Li, F.Y., Snow, V.O., Holzworth, D.P., and Johnson, I.R., 2010, Integration of a pasture model into APSIM, Proceedings of the 13th Australian Agronomy Conference, Lincoln, New Zealand (www.regional.org.au/au/asa/2010/farming-systems/simulation-decisionsupport/6993 lifyrevis.htm). Joint New Zealand - Australian Agronomy Society Conference, November 2010: Lincoln, New Zealand.

Li, Y., White, R., Chen, D., Zhang, J., Li, B., Zhang, Y., Huang, Y., and Edis, R., 2007, A spatially reference water and nitrogen management model (WNMM) for (irrigated) intensive cropping systems in the North China Plain: Ecological modelling v. 203, p. 395-423.

Probert, M.E., Dimes, J.P., Keating, B.A., Dalal, R.C., and Strong, W.M., 1998, APSIM's water and nitrogen modules and simulation of the dynamics of water and nitrogen in fallow systems: Agricultural Systems, v. 56, p. 1-28.

Rovita, D., and Killorn, R., 2007, Kinetics of nitrification in selected Iowa soils treated with Stay-N 2000: Communications in Soil Science and Plant Analysis, v. 38, p. 1949-1963.

Saggar, S., Andrew, R.M., Tate, K.R., Hedley, C.B., Rodda, N.J., and Townsend, J.A., 2004, Modelling nitrous oxide emissions from dairy-grazed pastures: Nutrient Cycling in Agroecosystems, v. 68, p. 243-255.

Saggar, S., Giltrap, D.L., Li, C., and Tate, K.R., 2007, Modelling nitrous oxide emissions from grazed grasslands in New Zealand.: Agriculture Ecosystems and Environment, v. 119, p. 205-216.

Snow, V.O., Shepherd, M.A., Cichota, R., and Vogeler, I., 2011, Urine timing: Are the 2009 Waikato results relevant to other years, soils and regions?, in Currie, L.D., and Christensen, C.L., eds., Adding to the Knowledge Base for the Nutrient Manager. http://flrc.massey.ac.nz/publications.html. Occasional Report No. 24. Fertilizer and Lime Research Centre, Massey University, Palmerston North, New Zealand, p. 14.

Verburg, K., Ross, P.J., and Bristow, K.L., 1996, SWIMv2.1 User Manual. Divisional Report No 130: Canberra, Australia, CSIRO Division of Soils, $107 \mathrm{p}$.

Vogeler, I., Cichota, R., Snow, V.O., Muirhead, R., and De Klein, C., 2010, A modelling analysis to determine N-risk indictors, in Edwards, G.R., and Bryant, R.H., eds., Australasian Dairy Science Symposium: Christchurch, NZ, p. 221-224.

Willmott, C.J., Ackleson, S.G., Davis, R.E., Feddema, J.J., Klink, K.M., Legates, D., R., O'Donnell, J., and Rowe, C.M., 1985, Statistics for the Evaluation and Comparison of Models: Journal Geophysical Research, v. 90, p. 8995-9005. 